\title{
THE EFFECT OF EXERCISE ON RENAL PLASMA FLOW IN NORMAL MALE SUBJECTS
}

\author{
By CARLETON B. CHAPMAN, AUSTIN HENSCHEL, JOHN MINCKLER, \\ ARTHUR FORSGREN AND ANCEL KEYS
}

(From the Laboratory of Physiological Hygiene, University of Minnesota, Minneapolis)

(Received for publication May 5, 1948)

The effect of exercise on renal function has been the target of numerous research projects, many of which have recently been reviewed by Herlitzka (1). It is generally agreed that exercise exerts an antidiuretic effect, that it depresses urea clearance, and that it increases the specific gravity of the urine. With the introduction of diodrast and of para-amino hippuric acid it became possible to estimate renal plasma flow with considerable accuracy, but these newer methods have not been applied extensively to the question of the effect of exercise.

In order to obtain quantitative information on the phenomenon a method was devised for following changes in renal plasma flow before, during, and after standard exercise of varying degrees of severity. The present report is concerned with the application of this test to normal young men.

\section{METHOD}

The subjects were required to omit the meal preceding the test and were not allowed to smoke for at least an hour before the experiment began. They were kept at complete bedrest for 40 minutes or longer before the beginning of the first basal period. Every effort short of the use of sedative drugs was made to allay anxiety.

The technique used is based on that originally described by Chasis $e t$ al. (2), but embodies certain important modifications made necessary by the test conditions. A constant injection apparatus similar to that described by Earle and Berliner (3) was substituted for the usual gravity type intravenous injection equipment. This device delivers exactly $0.966 \mathrm{cc}$. test solution per minute with great precision, not only during rest but also during exercise. Samples of urine were collected by voluntary micturition. In order to facilitate the collection of samples of urine, moderate water diuresis (urine flow of 10 to $15 \mathrm{cc}$. per minute) was instituted and the collection periods were lengthened to 20 minutes.

For the exercise, a motor-driven treadmill was used. No special training period was imposed but those subjects not already familiar with the treadmill were given short trials before experimental observations were begun. Three levels of activity were used: $A .3$ m.p.h. at zero per cent grade; $B .3$ m.p.h. at 5 per cent grade; and $C .3 .5$ m.p.h. at 10 per cent grade. The energy outputs at these levels of work, expressed as oxygen consumption per square meter body surface per minute, are 419,612 and $1070 \mathrm{cc}$. The first two levels placed no great strain even on a strictly sedentary individual. The third and highest level taxed normal, active male students only moderately but caused considerable discomfort in subjects accustomed to little or no strenuous exertion. The arm being used for injection of the clearance substance was kept in a relatively fixed position during exercise by having the subject rest his hand on the edge of a shelf placed directly in front of him and adjusted to a point several inches below the level of the shoulders. With the arm thus partly immobilized, the energy outputs for a given treadmill speed and grade are about one to 2 per cent less than if the arms are allowed to swing free. The results, however, are comparable from experiment to experiment since they were obtained under identical conditions; the only variable was the level of exercise being investigated.

The conditions under which renal plasma flow was followed during recovery were the same as those used for determining basal values. The subject walked a few feet to the bed after completing the work on the treadmill, and was required to lie immobile for the rest of the experiment. The constant injection apparatus was moved with the patient without interrupting the injection of the test substance.

The time sequence and complete data for a typical experiment in this series are given in Table $I$.

\section{MATERIAL}

Nine subjects were employed in the study. All were healthy male university students or instructors aged from 21 to 32 years. There was no evidence of renal disease in their histories or in the results of their urinalyses. Resting blood pressures were within the normal range in the entire group.

All clearance values were corrected to $1.73 \mathrm{sq} . \mathrm{m}$. of body surface using the formula of Dubois for total body surface.

Basal values were determined for two or three consecutive clearance periods in each experiment, the usual number being three. More than one experiment was done with eight of the nine subjects, and in six subjects, experiments were repeated six or more times. In order to gain some insight into the reliability of the method, all available basal data were utilized, regardless of variation between consecutive clearance periods or between sep- 
TABLE I

Sample experiment (Subject CBC, 24 November 1947; body surface 1.89 sq. m.). $P=$ mgm. PAH in 100 cc. plasma. $U=m g m$. $P A H$ in 1 cc. urine. $V=$ volume of urine per minute

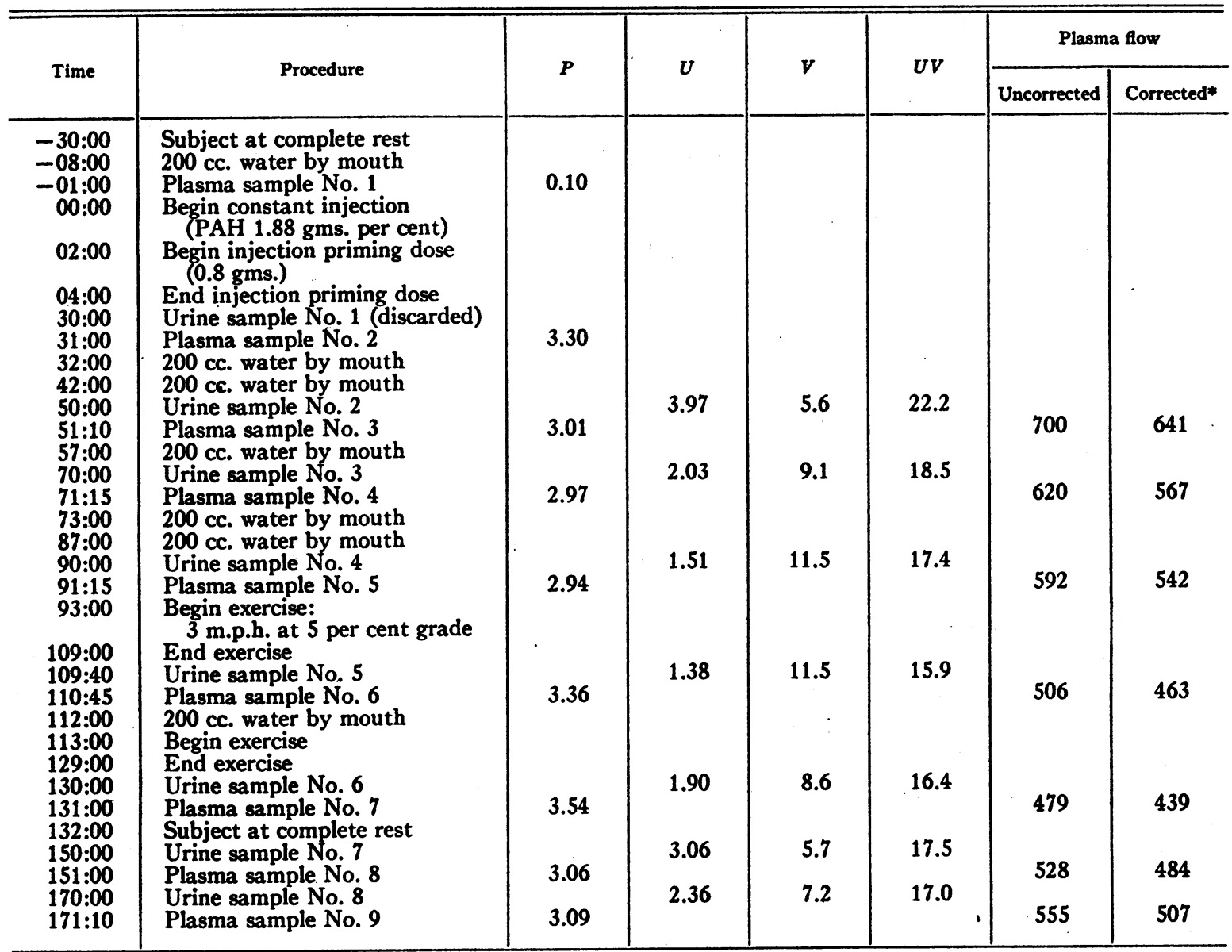

* Corrected to 1.73 sq. m. body surface.

arate experiments. This provided 59 experiments and a total of 140 clearance periods.

In order to evaluate the effect of exercise on basal plasma flow, no experiment was considered valid unless it included two or more basal values which were within 10 per cent of each other. This requirement resulted in the loss of several experiments in which only two basal values were determined. When three consecutive basal values were determined at least two figures were invariably obtained which did not exceed the variation allowed. For the studies on the light work load we obtained 12 valid tests on six subjects; for the intermediate load there were 13 valid tests on eight subjects, and for the heavy stress there were 10 valid tests on five subjects.

\section{RESULTS}

The method as described yielded an average basal renal plasma flow of $603.7 \pm 114 \mathrm{cc}$. for consecutive duplicate determinations and $613 \pm 107$ cc. for triplicates. Statistical treatment of the basal data (4) disclosed that repeatability for individual subjects was not high. The error (random variance) represents 57.1 per cent and 48.9 per cent of the interindividual variance in the case of duplicate and triplicate control data, respectively, the corresponding coefficients of consistency (rc) being 0.429 and 0.511 . The intraindividual standard deviations $\left(\sqrt{V_{W} I}\right)$ are \pm 89 and \pm 78 . For comparison, the corresponding interindividual standard deviations $\left(\sqrt{V_{W} D}\right)$ are \pm 175 and \pm 107 , respectively. A trend in both the duplicate and triplicate data was apparent. The successive means for the duplicate determinations were $621.5 \mathrm{cc}$. and $585.9 \mathrm{cc}$. and those for the triplicate data were $646.0 \mathrm{cc}$., $606.0 \mathrm{cc}$., and 587.7 cc. The differences between these means ap- 


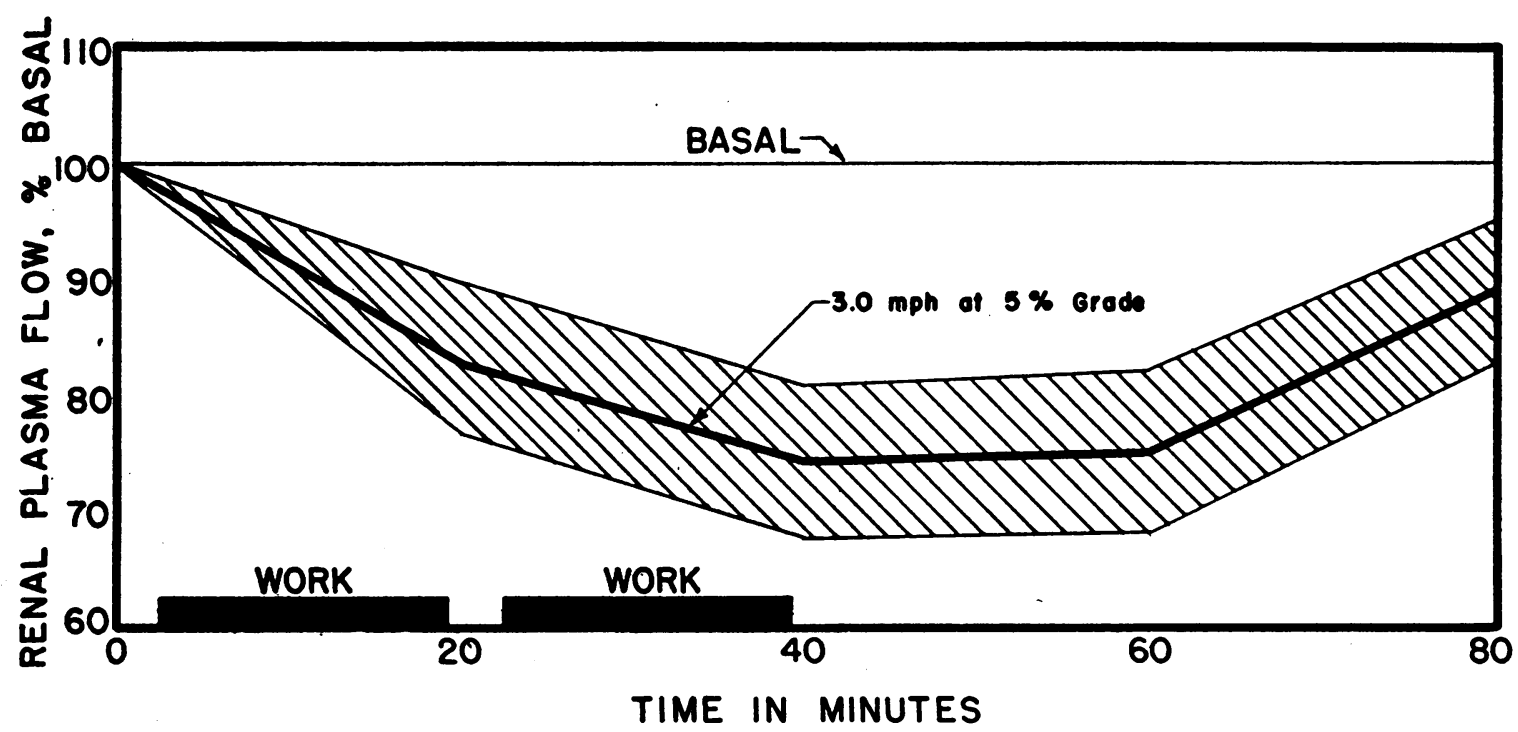

Fig. 1. Mean Changes (Heavy Line) in Renal Plasma Flow During and After the Intermediate GRADE OF WORK

The shaded area represents standard deviation.

proach significance for triplicate data and are significant for duplicate data.

The effects of exercise on renal plasma flow as revealed by our technique are set out in Figures 1 and 2, and in Tables I and II. Figures 1 and 2 show that there was a progressive decline in plasma flow as work proceeded. In no instance did the pattern of progressive decline in plasma flow fail to occur. The direct relationship between the amount of decline and the severity of

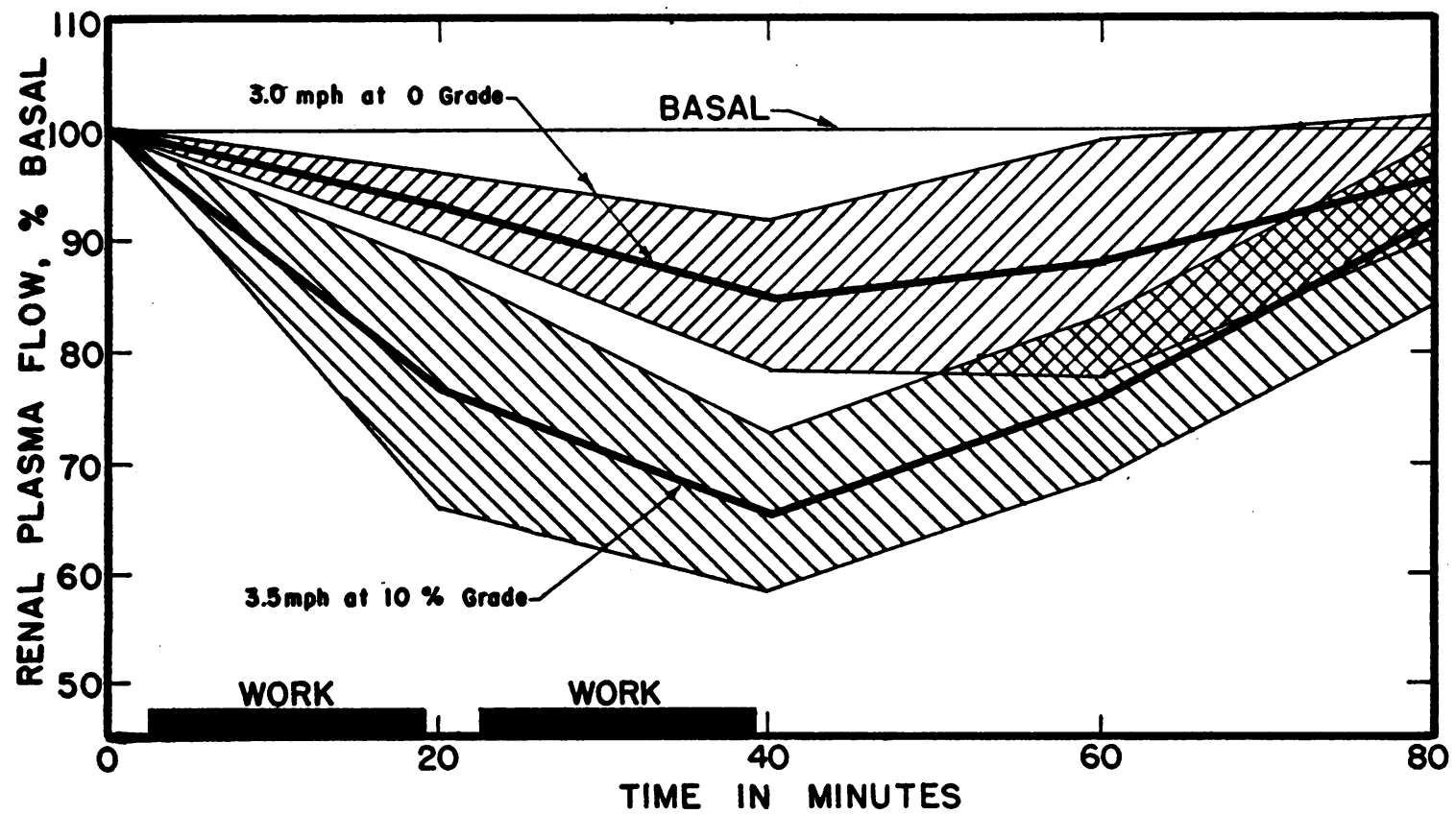

Fig. 2. Mean Changes (Heavy Line) in Renal Plasma flow During and After the Lightest and Heaviest Grades of Work

The shaded areas represent standard deviations. 
TABLE II

Mean renal plasma flow in work and in recovery from work at three levels of activity All values in cc. per minute for 1.73 sq. m. of body surface

\begin{tabular}{|c|c|c|c|c|c|}
\hline & Basal & Work 1 & Work 2 & Rest 1 & Rest 2 \\
\hline $\begin{array}{l}\text { Stress A } \\
\text { Stress B } \\
\text { Stress C }\end{array}$ & $\begin{array}{l}593.3 \pm 72.2 \\
595.7 \pm 65.2 \\
576.4 \pm 68.1\end{array}$ & $\begin{array}{l}551.3 \pm 74.5 \\
491.7 \pm 48.3 \\
435.4 \pm 42.8\end{array}$ & $\begin{array}{l}502.7 \pm 64.4 \\
438.1 \pm 27.1 \\
375.5 \pm 49.5\end{array}$ & $\begin{array}{l}528.8 \pm 84.3 \\
442.2 \pm 52.7 \\
459.7 \pm 72.1\end{array}$ & $\begin{array}{l}572.4 \pm 76.9 \\
516.2 \pm 42.3 \\
540.8 \pm 60.1\end{array}$ \\
\hline
\end{tabular}

the exercise is clearly apparent, although there is considerable overlapping when the standard deviations are plotted along with the means.

Recovery of the decline in renal plasma flow due to exercise is less predictable. With the lightest work load recovery was still incomplete 40 minutes after cessation of work, the residual decrement at that point showing a statistically significant difference from the basal value. The same was true for the heavier loads, but the amount of residual decrement bore no relation to the severity of the work.

In evaluating statistically the significance of changes under experimental conditions an $\mathrm{F}$-test for paired variates was employed. Both the magnitude of the changes and individual variation in response were taken into account. For each level of work, the differences between the basal renal plasma flow on one hand and those during work and recovery from work on the other proved to be significant or highly significant $(<5$ per cent, and $<1$ per cent, respectively). In evaluating the effect of increasing the severity of the work the differences observed at the lightest and the heaviest work loads $(3 \mathrm{~m} . \mathrm{p} . \mathrm{h}$. at zero grade, and 3.5 m.p.h. at 10 per cent grade, respectively) were tested by means of the same F-test. The differences were significant or highly significant throughout.

\section{DISCUSSION}

The two values for mean basal renal plasma flow in normal males as determined in this study $(603.7 \pm 114 \mathrm{cc}$. for duplicate and $613 \pm 107 \mathrm{cc}$. for triplicate determination) are comparable to that reported by Merrill (5) who obtained a value of $626 \pm 165 \mathrm{cc}$. in 39 experiments on 35 normal individuals (males and females), and to that obtained by Heller and Jacobson (6) which was $603 \pm 84.4$ cc. in eight normal males. Paraaminohippuric acid was used as the clearance sub- stance in all three studies but in the latter two, urethral catheterization was used for collection of samples of urine. Although the collection of urine samples by voluntary micturition instead of catheterization does not appear to have introduced serious error, it obviously limits the use of the method to subjects who have reasonable control over the initiation of micturition. It also imposes the necessity for working at relatively high rates of urine flow.

The possibility that water diuresis, itself a stress of a sort, may exert an independent action on renal plasma flow has never been adequately studied in the human subject, but Dicker and Heller (7) found that inulin and diodone clearances remained reasonably constant in rats at widely varying rates of urine flow. They state that "in the dog, as in man, diodone and inulin clearances do not rise with increase in urine flow." In our work no evidence of a trend was found when the corrected basal clearance values were plotted against the rates of urine flow. The mean rate of urine flow during basal determinations was $13.0 \pm 4.4$ cc. per minute.

The slight trend in consecutive basal values finds no ready explanation and is currently under further experimental investigation. It does not appear to be related to rates of urine flow. The same phenomenon is apparent in Benzinger's data (8) for three consecutive urea clearance values under basal conditions. In our own work there was a definite tendency for the clearance values to level off in the second and third basal periods and the basal value used for comparison with the values obtained during application of the stress was a mean, usually of the second and third basal figures. The use of such a mean value largely, if not entirely, compensated for the effect of the trend. 
Barclay and co-workers (9) measured inulin and diodrast clearances in eight normal subjects immediately after cessation of exercise (440 yard dash) and found that the renal plasma flow fell from 18 to 54 per cent of the resting values; ten to 40 minutes were required for the renal plasma flow to return to resting levels. The effect of sustained exercise was studied by means of a bicycle ergometer in two subjects and the renal plasma flow was found to decline steadily during the work, the duration and severity of which were not specified. White and Rolf (10) noted little change in renal plasma flow during light exercise but found it to fall markedly during heavy exercise. Merrill and Cargill (11) obtained a similar result in normal individuals performing work in both the upright and recumbent positions. Our results are generally in accord with those obtained by these workers but demonstrate more clearly that the extent of the decline in renal plasma flow is directly related to the severity of the exercise within certain, as yet incompletely defined, limits.

Recovery of renal plasma flow from the effects of exercise is considerably slower than is recovery as judged by pulse rate and blood pressure. It appears from our results that the rate and extent of recovery are not directly related to the severity of the work and that plasma flow is usually still somewhat depressed even after $40 \mathrm{~min}$ utes of rest following all three grades of exercise.

The mechanism by means of which exercise depresses renal plasma flow is uncertain and our work throws no new light on it. Barclay et al. (12) found that in exercise there is depression of the glomerular filtration rate and filtration fraction as well as of plasma flow. Since adrenalin, like pain and apprehension, produces an increase in filtration fraction while depressing plasma flow, they reason that the exercise effect is not mediated by adrenalin.

The chief significance of the diversion of blood from the kidney during exercise may be that more blood is made available for working muscles, a view suggested by Edwards et al. (13), among others. From our experience with two consecutive periods of exercise at the lightest work load, about $150 \mathrm{cc}$. of whole blood per minute are diverted from the kidney for circulation elsewhere. For the heaviest work load, the corresponding figure is about 330 cc., a not inconsiderable amount.

\section{SUMMARY}

1. Renal plasma flow was estimated from paraaminohippurate clearance in nine healthy men aged 21 to 32 years. In 59 experiments, providing 140 clearance periods, the basal mean for consecutive determinations in triplicate was 613 $\pm 107 \mathrm{cc}$. per minute, corrected to $1.73 \mathrm{sq}$. $\mathrm{m}$. body surface. Variability was analysed into interindividual, intraindividual, and random components.

2. During the first 16 minutes of walking on the motor-driven treadmill the renal plasma flow was decreased by an average of 6,17 and 25 per cent (of the resting control) at work levels, respectively, of 3.0 m.p.h. at zero grade, 3 m.p.h. at 5 per cent grade, and 3.5 m.p.h. at 10 per cent grade.

3. Continued walking for another 16 minutes yielded corresponding average reductions of 15 , 27 and 35 per cent of the resting control values.

4. Return of the renal plasma flow to basal levels was incomplete after 40 minutes of recovery following this exercise.

\section{BIBLIOGRAPHY}

1. Herlitzka, A., Fisiologia del Trabajo Humano. Editorial Americalee, Buenos Aires, 1945.

2. Chasis, H., Redish, J., Goldring, W., Ranges, H., and Smith, $H$., The use of sodium p-aminohippurate for the functional evaluation of the human kidney. J. Clin. Invest., 1945, 24, 583.

3. Earle, D. P., Jr., and Berliner, R. W., A simplified clinical procedure for measurement of glomerular filtration rate and renal plasma flow. Proc. Soc. Exper. Biol. \& Med., 1946, 62, 262.

4. Brozek, J., Simonson, E., Bushard, W., and Peterson, J., Effects of practice and the consistency of repeated measurements of accommodation and vergence. Am. J. Ophthalmol., 1948, 31, 191.

5. Merrill, A., Edema and decreased renal blood flow in patients with chronic congestive heart failure: Evidence of "forward failure" as the primary cause of edema. J. Clin. Invest., 1946, 25, 389.

6. Heller, B., and Jacobson, H., Personal communication, 1948.

7. Dicker, S., and Heller, H., The mechanism of water diuresis in normal rats and rabbits as analyzed by inulin and diodone clearances. J. Physiol., 1945, 103, 449.

8. Benzinger, T., Untersuchungen über den Einfluss 
schwerer Muskelarbeit auf die Nierenleistung. Arbeitsphysiol., 1935, 8, 142.

9. Barclay, J., Cooke, W., Kenney, R., and Nutt, M., The effect of exercise on the renal blood flow in man. J. Physiol., 1945-46, 104, $14 P$.

10. White, H., and Rolf, D., Effects of exercise on renal circulation. Federation Proc., 1948, 7, 133.

11. Merrill, A., and Cargill, W., The effect of exercise on the renal plasma flow and filtration rate of normal and cardiac subjects. J. Clin. Invest., 1948, 27, 272.

12. Barclay, J., Cooke, W., and Kenney, R., Observations on the effects of adrenalin on renal function and circulation in man. Am. J. Physiol., 1947, 151, 621.

13. Edwards, H., Cohen, M., Dill, D., and Thorndike, A., Jr., Renal function in exercise. Arbeitsphysiol., 1935-37, 9, 610. 